\title{
Certificación, recertificación y recontracertificación en anestesiología
}

\author{
Anesthesiology and certification
}

Héctor Lacassie ${ }^{1}$

L a actividad profesional en Chile cambió. Ya no es suficiente el título universitario primario. Para poder resaltar en alguna actividad es necesaria la diferenciación. Y la medicina en Chile no es ajena a este paradigma. Ya no es suficiente el título de médico cirujano para ejercer, se requiere una especialización. En anestesiología esta visión data de largo tiempo. Desde los inicios de la Corporación Nacional de Certificación de Especialidades Médicas (CONACEM), nuestra especialidad ha estado interesada en que se le reconozca como tal. De echo, anestesiología junto a ocho otras especialidades (cirugía, obstetricia, medicina interna, pediatría, traumatología y ortopedia, salud pública, medicina física y rehabilitación y urología), en 1987 fueron las primeras en acceder a la certificación de especialidad por CONACEM.

En anestesiología ya van más de 750 especialistas certificados por dicha entidad hasta 2015 (López JM, Hervé, L. Corporación Nacional de Certificación de Especialidades Médicas 1984-2015. Gráfica LOM, Santiago, 2016). De ahí en adelante el panorama cambió por dos grandes modificadores: 1) el Decreto Supremo (DS) N65 de 2015 del Ministerio de Salud y sus modificaciones posteriores (https://tinyurl.com/ y3virn88, acceso 8 de julio 2019) y 2) el fenómeno inmigratorio de anestesiólogos extranjeros.

El primer cambio fue la publicación del DS N57 con sus modificaciones hasta el Decreto N8 de 2017 (http://bcn.cl/1vqu2) en que se establece el reglamento de certificación de especialidades en medicina y odontología, además de las fechas de vigencia. En breve, se posterga la vigencia de los reconocimientos de certificación de especialidades hasta el 31 de diciembre de 2019, donde el plazo máximo de certificación será: 1) Universidades acreditadas: 10 años (hasta diciembre de 2029); 2) Certificados por CONACEM: 7 años (hasta diciembre de 2026); 3) Universidades no acreditadas: 5 años (hasta diciembre de 2024). En consecuencia, a contar del 1 de enero de 2020 se deberá iniciar el proceso de recertificación, a menos que esta fecha sea alterada, situación altamente probable*.

El segundo modificador ha sido la enorme inmigración extranjera de especialistas. Desde 2014, sobre 90\% de los postulantes a certificación por CONACEM son extranjeros y desde 2016, su número absoluto ha aumentado exponencialmente. En los años previos, los postulantes que rendían examen escrito eran menos de veinte al año. En 2016 aumentaron a 32; a 69 en 2017 y a 235 en 2018, donde sobre $90 \%$ de los candidatos son de origen venezolano. Es posible que estas cifras se mantengan o sigan aumentando dado el escenario político de la nación vecina.

Desde el punto de vista de la actividad certificadora, esto ha requerido un esfuerzo mayor para atender

Profesor Asociado Pontificia Universidad Católica de Chile.

Expresidente Comité de Anestesiología de CONACEM.

Fecha de recepción: 11 de julio de 2019

Fecha de aceptación:12 de julio de 2019

ORCID

https://orcid.org/0000-0001-5758-4113

Correspondencia:

Email: hlacassie@gmail.com

* Es altamente probable que la fecha clave de 2019 sea postergada por decreto. (Comunicación personal, Dr. José Manuel López, diciembre 2018). 
la demanda que ha crecido en más de $1.000 \%$ en 4 años. Sin embargo, esto no acaba ahí, ya que este enorme influjo de especialistas tendrá que ser recertificado al cabo de 7 años. Y a esto se sumará todo el cuerpo de anestesiólogos ya certificados que requerirán de recertificación.

La recertificación es un mundo en si mismo. Los criterios ya están definidos y se han publicado para su conocimiento (http://www.conacem.cl/recertificacion.asp). Ahora viene la etapa en que las personas acepten que esto es algo que llegó para quedarse y es una buena idea empezar a juntar los antecedentes mas temprano que tarde. Si bien este es un proceso voluntario, muchas instituciones de salud ya están solicitando la certificación como requisito para poder desempeñarse profesionalmente en ellas. La recertificación con seguridad va a seguir la misma vía.

En mi opinión, la exigencia de la certificación de especialidad es una necesidad básica para el correcto quehacer profesional y una responsabilidad ineludible. Toda medida que presione por ello favorecerá el engrandecimiento de nuestra especialidad, pero sobre todo, tender hacia el fin último, que es velar por la seguridad de nuestros pacientes. 